\title{
Abstract versus modality-specific memory representations in processing auditory and visual speech
}

\author{
BEATRICE DE GELDER and JEAN VROOMEN \\ Tilburg University, Tilburg, The Netherlands
}

\begin{abstract}
Serial recall of lip-read, auditory, and audiovisual memory lists with and without a verbal suffix was examined. Recency effects were the same in the three presentation modalities. The disrupting effect of a suffix was largest when it was presented in the same modality as the list items. The results suggest that abstract linguistic as well as modality-specific codes play a role in memory for auditory and visual speech.
\end{abstract}

In the 1970s, the notion of the modality effect came to refer to the difference between immediate memory for auditory and visual (understood as written) presentation of linguistic information (Penney, 1975). A special status was assumed for auditory events (Crowder \& Morton, 1969; Gardiner, 1983; Watkins \& Watkins, 1980), which rested on two specific characteristics that auditory short-term memory appeared to exhibit: the occurrence of an important effect of recency (i.e., better recall of the final item of a list) exclusively in the auditory modality and the reduction of that effect through presentation of a spoken suffix. Taken together, recency and suffix effects were the signature of immediate auditory memory, and they were at the core of the precategorical storage theory (PAS) developed by Crowder and Morton (1969).

The modality effect was, however, challenged when subsequent research revealed that visual input of spoken language (lipreading) behaved like auditory input. Experiments first carried out by Spoehr and Corin (1978) showed that recency of audiovisually presented lists (the listener could hear and see a speaker speaking) was disrupted as much by an auditory suffix as by a lip-read suffix. Later, Campbell and Dodd (1980) showed that lipread lists, in contrast with written lists, manifested recency effects similar to those manifested by heard lists. They also showed that a heard suffix interfered with lip-read recency. Comparing immediate memory for lip-read and audiovisual memory lists, Greene and Crowder (1984) found recency effects in both modalities. Moreover, both audiovisual and lip-read suffixes interfered with these recency effects. Gardiner, Gathercole, and Gregg (1983) compared free and backward recall of audiovisual memory lists with written lists. They found that a distracter task that involved lipreading had a more disruptive effect on audiovisual recency than did a distracter task that involved reading. Subsequent studies increasingly demonstrated the similarities between heard and lip-read speech

Correspondence should be addressed to B. de Gelder, Department of Psychology, Tilburg University, P.O. Box 90153, 5000 LE Tilburg, The Netherlands (e-mail: beadegelder@kub.nl). and the differences between these two speech input modalities and written presentation. Campbell and Dodd (1984) found that concurrent audition interfered with lipread recency, but not with small graphic (understood as written) recency effects. Also, concurrent articulation interfered with the graphic recency effect, but not with auditory and lip-read recency. These findings were taken as a challenge for the view that the modality effect reflects the peculiar characteristics of memory for acoustic information, and they led Crowder (1983) to reformulate the PAS theory.

A radical way to accommodate the preceding findings was to shift from a model based on auditory memory traces to one formulated in terms of abstract or amodal speech representations. As a matter of fact, the exclusive status of the auditory modality is implicitly challenged by the approach taken in speech perception research since the $1960 \mathrm{~s}$. One message from that research is that at least two stages of speech processing are involved: a stage of processing auditory information leading to an acoustic trace and a stage of phonological processing where phonological properties are extracted by a specialized speech processor. Whatever its precise meaning, a two-stage model would seem to be more open to the idea that speech can be conveyed through other sensory modes than only the auditory one. This leads naturally to the idea that the various physically different speech input modalities draw on underlying modality-independent phonological representations. Recency and suffix effects, once the hallmarks of auditory processing, would now signal the involvement of a specialized speech processor (Crowder \& Surprenant, in press; Mattingly, Liberman, Syrdal, \& Halwes, 1971; Morton, Marcus, \& Ottley, 1981). Many interpretations of recency and suffix effects in nonauditory speech modalities have taken that direction. It has been argued that commonalities in recency and suffix effects across different language input modalities reflect the operations of a specialized language-analyzing system (Crowder, 1983; Greene \& Crowder, 1984; Morton, Marcus, \& Ottley, 1981). In the same spirit, Shand and Klima (1981) proposed an abstract linguistic code mediating the process- 
ing of auditory as well as nonauditory linguistic information, a proposition in line with the notion of a specialized speech module.

However, the conclusion that the modality effect is a matter of abstract representations from which any aspect of sensory input modality is absent may be premature. The phenomenon of recency effects obtained with visual speech appears well established, but the situation of the suffix effects is less clear. As already noted, Greene and Crowder (1984) found recency and suffix effects with audiovisual and lip-read lists. More important for the present discussion is the fact that the suffix effects were larger when the modality of the memory list and the suffix matched. Thus, for an audiovisual list, an audiovisual suffix was most effective, whereas for a lip-read list, it was a lip-read suffix. These differential suffix effects were also obtained by Gathercole (1987). As reported, the finding was that lip-read recency was disrupted to the same extent by a lip-read suffix as by an audiovisual suffix, but audiovisual recency was only disrupted by an audiovisual suffix and not by a lip-read one. Gathercole concludes that the observed asymmetries do not represent a fundamental challenge for echoic theories, but they would seem to lend support to a modified version of auditorybased theories. The idea seems to be that the absence of an effect from a lip-read suffix on an audiovisual list restores the asymmetrical relation between memory for auditory and lip-read materials and thereby lends support to auditory-based theories after all.

Different theoretical proposals have been offered, each stressing the commonalities as well as the differences between immediate memory for hearing and lipreading. Nairne $(1988,1990)$ views recall as a reconstructive process, whereby the subject tries to interpret available traces against his or her background knowledge of possible recallable items. Traces consist of two kinds of features: modality-independent features derived from an inner speech code and modality-dependent features reflecting physical and/or perceptual characteristics of the presentation modality. The latter give rise to the recency effects. Lipreading is similar to hearing because they have the same modality-independent and modality-dependent features.

The separate-streams hypothesis defended by Penney (1989) offers a somewhat different model of short-term memory. The model addresses mainly the difference between spoken and written materials but allows predictions about the commonality between heard and lip-read speech. In Penney's view, input in the auditory stream is represented at the same time in an auditory code and in a phonological code. In contrast with Nairne's $(1988,1990)$ view, the auditory code is sensory based and is different from lip-read input. In other words, the difference between the two proposals would be that the separate-streams theory emphasizes the modality-dependent aspects while Nairne's theory stresses the underlying functional similarities of different speech input modalities. Penney's separate-streams theory would predict modality-specific suffix effects. To the extent that Nairne's theory emphasizes the symmetry of lip-read and heard modality-dependent features, it predicts cross-modal suffix effects. However, as Penney notes, current theoretical models are based on partial comparisons only.

The present experiment was undertaken in order to make a systematic comparison of recency and suffix effects for auditory, lip-read, and audiovisual material. All possibilities of combining lists and suffixes in these modalities were examined in a within-subject design. Ultimately, the theoretical question prompted by research in the visual speech modality is whether recency and suffix effects are produced in general auditory memory or are produced within a specialized speech processor.

\section{METHOD}

\section{Subjects}

One hundred thirty-three first-year students (male $=47$, female $=86$ ), all native Dutch speakers with no reported hearing or seeing deficit, were tested.

\section{Preparation of the Stimulus Tape}

A female speaker reciting the digit lists was recorded on Sony U-matic video. The picture showed the whole of the speaker's face under even lighting conditions. In the audiovisual presentation, one could hear the speaker and watch her lips move. For the visual presentation, the sound track was deleted, and the subjects had to rely entirely on lipreading. For the auditory presentation, the digits were spoken into an Uher reel-to-reel tape recorder. This soundtrack was inserted into the videotape showing the speaker's face while she was sitting quietly.

\section{Design and Stimuli}

Lists of seven digits were presented at a rate of one item per second. The stimuli were drawn from the Dutch monosyllabic digits 0-6 and 8. There were three presentation modes (audiovisual, auditory, and lip-read) and four suffix conditions (a no-suffix condition in which a 200 -msec tone of $1000 \mathrm{~Hz}$ was presented, and three speech suffixes [STOP] presented in either the audiovisual, auditory, or lip-read mode). Each of the 12 conditions consisted of eight lists, for a total of 96 experimental lists. Across lists in every condition, each digit occurred once in each serial position. Within a list, no more than two consecutive digits increased or decreased in a row. Suffixes were presented in rhythm with digit presentation. Lists were preceded 6 y a $200-\mathrm{msec}$ warning tone. To ensure that the subjects were watching the screen during presentation of an audiovisual or lip-read suffix, the face of the speaker faded out right after the presentation of the list, or in the case that a suffix was presented, it faded after that suffix and was immediately followed by a circle appearing for $1 \mathrm{sec}$ in the middle of the screen. A green circle signaled the start to respond; a red circle (catch trial) signaled the subjects to write down crosses on the response sheet.

\section{Procedure}

Each presentation mode of the memory lists was given in two blocks of 16 trials each. The order of the blocks was always audiovisual, auditory, visual, visual, auditory, and audiovisual. In each block, the suffix conditions were presented in random order, with no more than two consecutive trials in the same suffix condition. Each block was preceded by a warm-up list. Each block contained one catch trial. The catch trial appeared, unknown to the subjects, progressively later across the consecutive blocks. Instructions specified the length of the lists and the number of trials. The subjects were told to look at the screen until the response signal (a green 
or red circle) appeared and to write down their responses from left to right on a prepared sheet. They were given $15 \mathrm{sec}$ for this. The subjects were told that responses would be scored as correct only if the digits were in the correct position. They were encouraged not to leave blanks but to guess if they were unsure. They were closely supervised during the experiment to ensure that they followed instructions. The subjects were tested in small groups. The experiment was preceded by a practice session in which all experimental conditions occurred twice, including three catch trials.

\section{RESULTS}

Figure 1 displays the mean proportion correct recall as a function of the serial position, separately for the each presentation mode of list and suffix. Clearly, in all presentation modes of the memory lists there were substantial recency effects if no suffix was given. An auditory suffix decreased the magnitude of the recency in auditory and audiovisual lists, but had little effect in lip-read lists. A lip-read suffix decreased recency in lip-read lists, but not in auditory lists. An audiovisual suffix was effective in lip-read and audiovisual lists.

These generalizations were supported by a 3 (list mode) $\times 4$ (suffix) $\times 7$ (serial position) analysis of variance (ANOVA) on the proportion of correct responses. There was a significant main effect of list mode $[F(2,264)=$ 96.25, $M S_{\mathrm{e}}=16.86, p<.001$ ]. Post hoc tests (Scheffe, $\alpha=.01$ ) showed that this was mainly due to the lower recall for the lip-read lists. The effect of a suffix was significant $\left[F(3,396)=40.70, M S_{e}=1.74, p<.001\right]$, as was the effect of serial position $[F(6,792)=94.00$, $\left.M S_{\mathrm{e}}=8.75, p<.001\right]$. There were significant interactions: list mode $\times$ serial position $[F(12,1584)=8.61$, $\left.M S_{\mathrm{e}}=0.14, p<.001\right]$, suffix $\times$ serial position $\left[F(18,2376)=17.79, M S_{\mathrm{c}}=0.27, p<.001\right]$, and list mode $\times$ suffix $\left[F(6,792)=4.06, M S_{c}=0.14, p<\right.$ $.001]$. Inspection of Figure 1 reveals that these effects were mainly located in the recency part of the curve (Position 7), which was signaled by a significant second-order interaction of list mode, suffix, and serial position $\left[F(36,4752)=7.05, M S_{\mathrm{e}}=0.09, p<.001\right]$.

To analyze this second-order interaction, an ANOVA was performed on recency as measured by the difference in number of items recalled between the last serial position and the average of the other positions. Mean recency scores are presented in Table 1 . There was a main effect of presentation mode of the list $[F(2,264)=12.10$, $M S_{e}=0.28, p<.001$ ], mainly because visually presented lists had smaller recency effects. The effect of a suffix on recency was significant $[F(3,396)=46.32$, $\left.M S_{\mathrm{e}}=1.01, p<.001\right]$. Of interest was an interaction among list mode and suffix $\left[F(6,792)=18.49, M S_{\mathrm{e}}=\right.$ $0.34, p<.001]$. The data in Table 1 suggest that in lipread lists, a lip-read suffix was more effective than an auditory suffix, whereas in auditory lists, an auditory suffix was more effective than a lip-read one. This interpretation was tested statistically by an interaction contrast based on the error term of the omnibus interaction (Boik, 1979). Gabriel's simultaneous procedure for partial interaction tests $(\alpha=.01)$ revealed that the effect of a suffix was not identical for auditory and lip-read lists. Sheffé's method for interaction contrast tests $(\alpha=.01)$ showed that with auditory lists, an auditory suffix was much more effective than a lip-read suffix, whereas with lip-read lists, a lip-read suffix was more effective than an auditory one.

Sheffés method for simple contrast tests indicated that there was no difference in recency between auditory, lipread, and audiovisual lists in the no-suffix condition (tested

$$
\text { Auditory }
$$

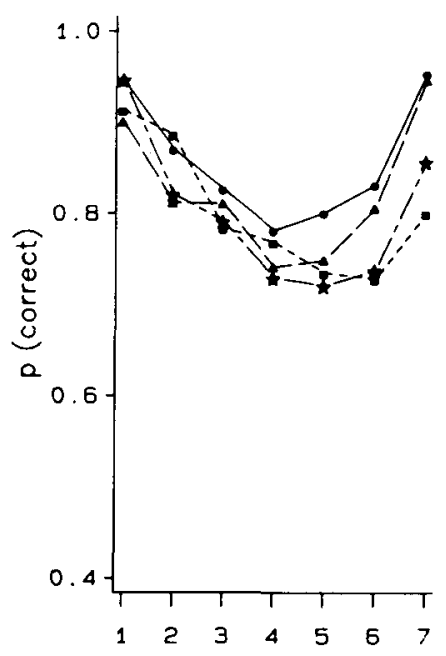

Lipread
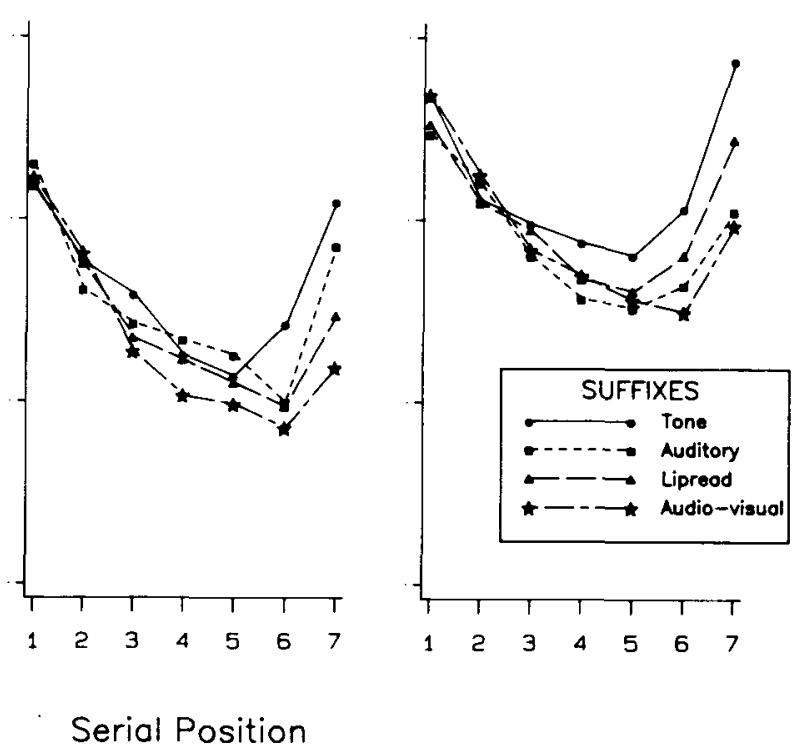

Serial Position

\section{Audio-visual}

Figure 1. Proportion of correct responses as a function of the serial position for auditory, lip-read, and audiovisual memory lists. 
Table 1

Mean Recency Scores for Each Suffix and List Mode

\begin{tabular}{lcccc}
\hline & \multicolumn{4}{c}{ List Mode } \\
\cline { 2 - 5 } \multicolumn{1}{c}{ Suffix } & Auditory & Visual & Audiovisual \\
\hline Tone & .11 & .11 & .16 & .13 \\
Auditory & .00 & .07 & .04 & .03 \\
Visual & .15 & .01 & .10 & .08 \\
Audiovisual & .07 & -.04 & .01 & .01 \\
& .08 & .04 & .08 & \\
\hline
\end{tabular}

at $\alpha=.05$ ). An auditory suffix decreased recency in auditory and audiovisual lists $(\alpha=.01)$, but not in lip-read lists (tested at $\alpha=.05$ ). A lip-read suffix was only effective in lip-read lists $(\alpha=.01)$. An audiovisual suffix decreased recency in lip-read and audiovisual lists (all comparisons at $\alpha=.01$ ), but it did not reach significance in auditory lists (tested at $\alpha=.05$ ).

\section{DISCUSSION}

In the present experiment, we investigated the issue of a common memory for auditory, lip-read, and audiovisual speech by comparing recency and suffix effects in these modalities. In the absence of a suffix, all modalities did have the same amount of recency. This result suggests that the same mechanisms are responsible for the observed recency effects, independent of whether the lists presented are auditory, visual, or audiovisual. But, when there was a suffix, the disruptive effect on recency was a function of the modality of list and suffix presentation. In auditory lists, an auditory suffix was effective but not a lipread one, and the reverse pattern was found in lip-read lists. This result suggests a modality-specific component of memory representations. Our basic question then is how to combine the suggestion of common memory processes derived from similar recency effects with the suggestion of modality-specific representations derived from the differential suffix effects. Since data from recency and suffix effects pull in different directions, we will discuss the two sets of results in turn. Before turning to the discussion, two remarks must be made.

We want to argue that the interpretation of the suffix effects is not hindered by ceiling performance, which might obscure possible consequences. The important finding in this study is that performance dropped selectively, depending on the modality of the list and the suffix. The same materials have been used to study recall in children and in a group of reading-disabled adult subjects known to suffer from memory impairments (de Gelder \& Vroomen, in press). Performance in these groups was poorer, and there were no ceiling effects. Yet, exactly the same pattern of recency and suffix effects as here were observed.

Secondly, the small cross-modal suffix effects are not due to the fact that the subjects were not paying attention to the other input channel. In all conditions, the subjects were watching the screen until a circle appeared before they were allowed to respond. That the subjects complied with this instruction can be seen in the condition where lists were presented audiovisually. There was, in that condition, a small disruptive effect of a lip-read suffix, which indicates that although the items could be heard as in the auditory list, the subjects were watching the screen and processed the lip-read suffix. The compellingness to process lip-read speech is also demonstrated in the classical McGurck illusion, where subjects are unable to disregard the lip-read information from what they hear (McGurck \& MacDonald, 1976). With respect to auditory suffixes, the situation is even more clear. Auditory suffixes are not under attentional control (Balota \& Engle, 1981; Hitch, 1975), and there was no conceivable way the subjects could have avoided processing them.

Let us now look in more detail at the recency phenomena. Earlier studies suggested that lip-read lists show recency (Campbell \& Dodd, 1980, 1984) and that, in general, memory processes for lip-read and auditory lists are more similar to each other when contrasted with memory processes for written presentation of linguistic items. The extent of this similarity is made clear by the results of the present experiment. Overall, the data do seem to support the notion that it is the common use of the linguistic speech processor that gives rise to the observed recency effects in the two speech input modalities. It is the engagement of the speech processor that generates recency effects, in contrast with what happens in the processing of written input, with music, or with environmental sounds (Crowder \& Surprenant, in press).

A potential source of concern for the linguistic explanation is the difference in overall performance between the auditory and lip-read modalities. Indeed, we found that recall in the lip-read modality is poorer than in the auditory modality. If the recency effects in the auditory and lip-read modality are the signature of the operations of the speech processor extracting phonological information, why would performance for the two types of lists be different? There are several possible answers to this question. One is that the phonetic decoding of lip-read speech is more difficult because, compared with the auditory input, the visual speech information is phonetically underspecified. There is, for example, no voicing information in the visual speech signal. This could result in more effortful phonetic decoding operations during lipreading, and it could lead to interference with rehearsal strategies. Another effect of the poor phonetic representation of lip-read speech is that lip-read items become less discriminable from each other and that they might be decoded wrongly. For example, the lip-read Dutch words for one and three, /e:n/ and /dri/, respectively, look quite similar-a fact that increases the chance of confusion. Thus, although the overall performance with visual speech is worse than with auditory or audiovisual speech, it is still possible that in all these cases memory performance is based on the involvement of the speech processor. On this picture, the relatively poor performance with lip-read lists would be explained by rather peripheral distinctions between the input modalities.

One aspect of the present results deserves further attention and complements the above discussion. The bimodal condition can be viewed as a situation where the 
same information is presented in two parallel modalities. On the basis of available evidence of the effects of bimodal presentation on retention, we should expect that it increases recall (e.g., Broadbent, 1956). In an overview of these studies, Penney (1989) concluded that presentation of items to two sensory modes, rather than to one, can improve short-term retention, but that presentation asymmetries between auditory and visual (written) presentation have so far made conclusions difficult. The present study offers a more interesting situation for evaluating the advantages of double presentation since, here, the two input modalities are largely symmetrical and recall does not raise issues of response bias (spoken recall for auditory as well as for written presentation of digits; e.g., see Frick, 1985). Our data show that bimodal presentation does not improve recall.

How helpful is the notion of modality-independent representations when it comes to explaining the suffix effects? If one favors the notion of abstract, linguistic representations on which recency effects are based, one should expect that a lip-read suffix has an effect on auditory recency and vice versa. Effects of audiovisual suffixes should be the same as those observed for a suffix in either of the two modalities separately. Neither of these predictions were, however, confirmed. Yet, the suffix effects obtained have been anticipated in previous studies where partial comparisons between modalities were made. In fact, read properly, Gathercole's (1987) results show that lip-read recency was disrupted by lip-read and audiovisual suffixes. Similarly, auditory recency was disrupted by a same modality suffix - the auditory one. This result goes very much in the direction of modality specificity of suffix effects as observed in Greene and Crowder (1984).

One could argue that it is reasonable that a lip-read suffix is less effective than an auditory suffix, even when both make use of the same speech processor. A lip-read suffix could be less effective than an auditory one because the former is phonetically underspecified. Campbell, Garwood, and Rosen (1988) favored this explanation when finding that a lip-read speech suffix combined with a buzz tone indicating pitch disrupted recall more than did a simple lip-read suffix. They argued that the more specified phonetically the suffix, the more potentially disruptive it would be. However, phonetic underspecification as used by Campbell et al. seems insufficient to explain our findings. We found that an auditory suffix, which is phonetically more specified than a lip-read suffix, has a less disruptive effect on lip-read recency than does the phonetically underspecified lip-read suffix. This is clearly in contradiction with the previous argument.

As a matter of fact, the disruptive effect of a suffix might not merely consist in overwriting of the most recent traces of the speech processor. Another alternative is that retrieval cues (temporal or whatever they may be) are attached to the suffix, which makes the final memory item less distinct or accessible. That is why a suffix is presented in rhythm with item presentation; otherwise, retrieval cues would probably not be connected to the suffix. On this account, the disruptive effect of a suffix will depend on the ease by which it can be excluded from the memory items. The more similar a suffix is to the memory items, the higher the probability of attaching cues to the suffix will be, and the more disruptive its effect. The similarity depends, among other things, on the physical characteristics of the input format. An auditory suffix is physically more similar to an auditory memory list than a lip-read suffix, and that is why the former is, in this case, more effective. The same reasoning can, mutatis mutandis, be applied to a lip-read suffix. In the case of an audiovisual list, auditory, visual, and audiovisual suffixes are all more or less effective because they all resemble the input format of the memory items in some way. Since the input formats of the final item and the suffix play a role, it follows that the physical characteristics of the list items are in some way retained in memory. It is, however, not clear whether these physical characteristics play a role in the recency effect. If they did, there would be no intrinsic reason to expect that auditory and lip-read recency effects are equivalent, because the two are quite distinct in their physical characteristics.

Turning from experimental to neuropsychological evidence, it appears that abstract as well as modality-specific speech representation come into play. Campbell, Landis, and Regard (1986) describe a patient suffering from a lipreading impairment in the absence of any indication of an auditory speech processing impairment. Other studies have shown the relative independence of processing in the two speech input modalities. We observed subjects whose auditory and lipreading skills were normal but who nevertheless did not integrate information from the two sources (de Gelder, Vroomen, \& van der Heide, 1991). On the other hand, other neuropsychological data seem to point to underlying commonalities. We have observed phonological impairments in dyslexics for auditory speech categorization that were correlated with a reduced ability to identify lip-read speech (de Gelder \& Vroomen, 1988 , in press).

In conclusion, the recency effects observed in this study suggest that the actual memory representations have modality-specific and modality-independent components. In that sense, the present results complicate the notion of an intimate link between memory and speech processing. The notion that memory is specialized because it is part of the speech processor looks premature. Our data stress the need for research that must further untangle the relation between specialized speech processes and specialized memory processes. One may ask to what extent a distinction must be introduced between memory as part of ongoing speech decoding and memory as manifested in recall performance. This issue is of theoretical as well as practical interest. Not surprisingly, impairments on recall tasks are currently explained in two different ways, depending on whether memory processes are blamed (Gathercole \& Baddeley, 1990) or phonological processing deficits are suspected (de Gelder \& Vroomen, 1991; Shankweiler, Liberman, Mark, Fowler, \& Fischer, 1979). 


\section{REFERENCES}

Balota, D. A., Engle, R. W. (1981). Structural and strategic factors in the stimulus suffix effect. Journal of Verbal Learning \& Ver bal Behavior, 20, 346-357.

BoIK, R. J. (1979). Interaction contrasts in the analysis of variance. Psychological Bulletin, 86, 1084-1089.

BroAdBENT, D. E. (1956). Successive responses to simultaneous stimuli. Quarterly Journal of Experimental Psychology, 8, 154-162.

CAMPBELL, R., \& DodD, B. (1980). Hearing by eye. Quarterly Journal of Experimental Psychology, 32, 85-99.

CAMPBELL, R., \& DoDD, B. (1984). Aspects of hearing by eye. In H. Bouma and D. G. Bouwhuis (Eds.), Attention and Performance $X$ (pp. 299-312). Hillsdale, NJ: Erlbaum.

Campbell, R., Garwood, J., \& Rosen, S. (1988). Adding sound to lipread lists: The effects on serial recall of adding an auditory pulse train and a pure tone to silently lipread lists. Memory \& Cognition, 16, 210-219.

Campbell, R., Landis, T., Regard, M. (1986). Face recognition and lipreading: A neurological dissociation. Brain, 109, 509-521.

Crowder, R. G. (1983). The purity of auditory memory. Philosophical Transactions of the Royal Society of London, B302, 251-265.

Crowder, R. G., \& Morton, J. (1969). Precategorical acoustic storage (PAS). Perception \& Psychophysics, 5, 363-373.

Crowder, R. G., \& Surprenant, A. (in press). On the linguistic module in auditory memory. In B. de Gelder \& J. Morais (Eds.), Language and literacy. London: Eribaum.

de Gelder, B., \& VROOMEN, J. (1988, August). Bi-modal speech perception in young dyslexics. Paper presented at the sixth Australian Language and Speech Conference, Sydney.

de Gelder, B., \& Vroomen, J. (1991). Phonological deficits: Beneath the surface of reading-acquisition problems. Psychological Research, 53, 88-97.

DE Gelder, B., \& VROOMEN, J. (in press). Phonological memory deficits in young and adult dyslexics. In B. de Gelder \& J. Morais (Eds.), Language and literacy. London: Erlbaum.

de Gelder, B., VRoomen, J., \& VAN der Heide, L. (1991). Face recognition and lipreading in autism. European Journal of Cognitive Psychology, 3, 69-86.

FrICK, R. W. (1985). Testing visual short-term memory: Simultaneous versus sequential presentations. Memory \& Cognition, 13, 346-356.

Gardiner, J. M. (1983). On recency and echoic memory. Philosophical Transactions of the Royal Society of London, B302, 267-282.

Gardiner, J. M., Gathercole, S. E., \& GregG, V. H. (1983). Further evidence of interference between lipreading and auditory recency.
Journal of Experimental Psychology: Learning, Memory, \& Cognition, 9, 328-333.

GATHERCOLE, S. E. (1987). Lip-reading: Implications for theories of short-term memory. In B. Dodd \& R. Campbell (Eds.), Hearing by eye: The psychology of lip-reading (pp. 227-241). London: Erlbaum. Gathercole, S. E., \& Baddeley, A. D. (1990). Phonological memory deficits in language disordered children: Is there a causal connection? Journal of Memory \& Language, 29, 336-360.

Greene, R. L., \& Crowder, R. G. (1984). Modality and suffix effects in the absence of auditory stimulation. Joumal of Verbal Learning \& Verbal Behavior, 23, 371-382.

HгтсH, G. (1975). The role of attention in the visual and auditory suffix effect. Memory \& Cognition, 3, 501-505.

Mattingly, I. G., Liberman, A. M., Syrdal, A. K., \& Halwes, T. (1971). Discrimination in speech and non-speech modes. Cognitive Psychology, 2, 131-157.

McGurck, H., MacDonald, J. (1976). Hearing lips and seeing voices. Nature, 264, 746-748.

Morton, J., Marcus, S. M., \& OTtley, P. (1981). The acoustic correlates of "speechlike": A use of the suffix effect. Joumal of Experimental Psychology: General, 110, 568-593.

NAIRNE, J. S. (1988). A framework for interpreting recency effects in immediate serial recall. Memory \& Cognition, 16, 343-352.

NaIRNE, J. S. (1990). A feature model of immediate memory. Memory \& Cognition, 18, 251-269.

PENNEY, C. G. (1975). Modality effects in short-term verbal memory. Psychological Bulletin, 82, 68-84.

PEnNey, C. G. (1989). Modality effects and the structure of short-term verbal memory. Memory \& Cognition, 17, 398-422.

Shand, M. A., \& Kuima, E. S. (1981). Nonauditory suffix effects in congenitally deaf signers of American Sign Language. Journal of Experimental Psychology: Human Learning \& Memory, 7, 464-474.

Shankweiler, D., Liberman, I. Y., Mark, L. S., Fowler, C. A., \& FisChER, F. W. (1979). The speech code and learning to read. Journal of Experimental Psychology: Human Learning \& Memory, 5, 531-545.

SPOEhr, K. T., CORN, W. J. (1978). The stimulus suffix effect as a memory coding phenomenon. Memory \& Cognition, 6, 583-589.

WatkIns, O. C., \& WAtkins, M. J. (1980). The modality effect and echoic persistence. Joumal of Experimental Psychology: General, 109, 251-278.

(Manuscript received August 19, 1991; revision accepted for publication November 19, 1991.) 